\title{
Evaluation of Ultra-High-Performance Liquid Chromatography (HPLC) Tandem Mass Spectrometry for Determination of Avermectin Residues in Milk
}

\author{
O.V. Bayer ${ }^{1}$, O.V. Kaminska ${ }^{1}$, O. V. Bondarets ${ }^{1}$, O. S. Yaremchuk ${ }^{2}$, O. I. \\ Skoromna ${ }^{2}$, S. V. Midyk ${ }^{3}$, L. V. Shevchenko ${ }^{3}$, V. M. Mykhalska ${ }^{3}$, O. M. Stupak ${ }^{1}$, N. \\ V. Liniichuk ${ }^{1}$ \\ ${ }^{1}$ State Research Institute for Laboratory Diagnostics and Veterinary and Sanitary Expertise, 30, \\ Donetska st., Kiev, Ukraine, 02000 \\ https://orcid.org/0000-0001-7303-1519; https://orcid.org/0000-0003-2650-7056; \\ https://orcid.org/0000-0001-5391-3530 \\ ${ }^{2}$ Vinnytsia National Agrarian University, 3 Soniachna St., bldg. 3, Vinnytsia, Ukraine, 21000 \\ https://orcid.org/0000-0002-3283-6107; https://orcid.org/0000-0003-1332-5579 \\ ${ }^{3}$ National University of Life and Environmental Sciences of Ukraine, 15, Heroyiv Oborony Str., Kyiv, \\ Ukraine, 03041, \\ http://orcid.org/0000-0002-2682-2884; http://orcid.org/0000-0001-7472-4325; \\ http://orcid.org/0000-0003-0578-8856 \\ E-mail: svit.mid@gmail.com
}

Received: 18.11.2019. Accepted: 07.12.2019

\begin{abstract}
The study was conducted to evaluate the applicability of ultra high-performance liquid chromatography - tandem mass spectrometry method (UHPLC-MS/MS), establish the MS/MS detection parameters and determine the validation characteristics for the analysis of residual content of avermectins in milk. The UHPLC-MS/MS method has proved to be accurate, practical and universal. This was confirmed by Decision limit (CCa) data: abamectin - $12.56 \mu \mathrm{g} / \mathrm{kg}$, doramectin - $17.74 \mu \mathrm{g} / \mathrm{kg}$, eprinomectin $24.02 \mu \mathrm{g} / \mathrm{kg}$, ivermectin $-12.53 \mu \mathrm{g} / \mathrm{kg}$, moxidectin $-44.69 \mu \mathrm{g} / \mathrm{kg}$, recovery is $88.7-110 \%$. The data obtained for assessing the suitability, accuracy and reproducibility of the results meet the requirements of the European Directive (2002/657/EC). The efficient ultra high-performance liquid chromatography tandem mass spectrometry (UHPLC-MS/MS) method that was developed and adopted for routine use by the laboratories of veterinary medicine, allows to detect residual quantities of 5 avermectins used in animal breeding for the prevention of helminthiases in food products including milk.
\end{abstract}

Key words: Avermectins; UHPLC-MS/MS; Validation; Milk

\section{Introduction}

Evaluation of food products' safety lies in determination of toxic substances (Yakubchak et al., 2018) and residues of veterinary drugs used in the process of productive animal breeding. Avermectins (AVM) are the veterinary drugs widely used in animal and cattle breeding for prevention and treatment of diseases caused by endo- and ectoparasites. Avermectins are the waste products of Streptomyces avermitilis fungi. It's difficult to clearly classify them and relate solely to chemical or biological group of compounds with neurotoxic activity in organism of human. After getting to the body of invertebrates by contact or through the intestines, they activate I-glutamine and gamma-Aminobutyric acid in the peripheral nervous system with the same regulator-receptor as Acetylcholinesterase for Acetylcholine (Tengteng et al., 2019). The most frequently used and permitted veterinary medications for cattle treatment are: Abamectin (ABA), Doramectin (DORA), Ivermectin (IVER), Eprinomectin (EPRI), and Moxidectin (MOXI) (Dupuy et al., 2001; He et al., 2005; Baoliang et al., 2006; Durden et al., 2007).

As any toxic substances, avermectins can have negative effect on environment (Voitsitskiy et al., 2019; Lumaret et al., 2012), health of productive animals (Kose et al., 2016) and people (Miyajima et al., 2016) - after getting to the body together with food products of animal origin, including milk. For this reason, European Union countries have regulatory acts for usage and permitted residual content of avermectins in products of animal origin (Codex Alimentarius, 2014; Commission Regulation, 2009). According to European regulations, MRL (Maximum Residue Limit) in milk was established only for Eprinomectin (20 $\mu \mathrm{g} / \mathrm{kg})$ and for Moxidectin 
(40 $\mu \mathrm{g} / \mathrm{kg}$ ) (Wu et al., 2001). Codex Alimentarius (International food standards) (Codex Alimentarius, 2014) sets the following MRLs for milk: Doramectin - $15 \mu \mathrm{g} / \mathrm{kg}$, Ivermectin - $10 \mu \mathrm{g} / \mathrm{kg}$; there are no regulatory restrictions for Abamectin.

To determine the residual content of avermectins in food and animal tissues, a number of techniques with a different sensitivity range was proposed (He et al., 2005; Wu et al., 2001). The enzyme-linked immunosorbent assay (ELISA) is used to determine the residual content of avermectins in livestock products. This method is rather convenient for samples screening, for it does not involve complex sample preparation and equipment. However, it also has some disadvantages. As seen from the above, the test systems are designed exclusively for the individual matrices (eggs, muscles, milk) and do not cover the entire list of existing avermectins.

There is another method of detecting avermectins' residues in biological samples, which involves the usage of immunoaffinity columns (Wu et al., 2001) for samples preparation. Its principle also lies in formation of antigen-antibody complex.

Analytical method of analysis by high performance liquid chromatography (HPLC). The residues of avermectins in biological matrices are usually determined using solid phase extraction and liquid chromatography with a fluorescence detector (He et al., 2005; Kaufmann et al., 2014; Danaher et al., 2006; Giannetti et al., 2011; de Souza Santos Cheibub et al., 2019), as well as liquid chromatography combined with tandem mass spectrometry (Huang et al., 2014; Ortiz et al., 2017; Manjusha R. Jadhav et al., 2019; Yashpal et al., 2018; Sheridan and Desjardins, 2006).

The ultra-high-performance liquid chromatography tandem mass spectrometry method (UHPLC-MS/MS) is a confirmatory method for detecting the level of avermectins in animal tissues and milk. It has higher sensitivity and encompasses wide range of analytes. The residual content of all avermectins in animal products can be determined with the help of UHPLC-MS/MS (Nurullah Ozdemir and Tahir Kahraman, 2016; Durden, 2006). Some methods developed for ultra high-performance liquid chromatography-mass spectrometers are highly costly, especially those that are designed to use solid-phase columns for better cleaning of the supernatant.

The objective of this study was the modification and validation of UHPLC-MS/MS method applicable for determination of avermectins' residues in milk on the level of the method's detection limit, since there is MRL regulation for two substances: moxidecin - $40 \mu \mathrm{g} / \mathrm{kg}$ and epinomectin - $20 \mu \mathrm{g} / \mathrm{kg}$. Samples are typically extracted using organic solvent and cleaned up by the method of liquid-liquid extraction (LLE), which makes it more affordable, faster and more sensitive.

\section{Materials and Methods}

The residual quantity of avermectins were detected by liquid chromatograph ACQUITY UPLC H-Class using a triple-quadrupole mass spectrometer Waters XEVO TQ-S micro (USA, Durham, NC) with reverse phase analytical column ACQUITY UPLC BEH C18 (1.7 $\mu$, $100 \mathrm{~mm} \times 2 \times 2.1 \mathrm{~mm})$.

During the preparation of milk samples the following equipment was used: Eppendorf 5810 R Centrifuge (Germany, Gamburg) with maximum acceleration of $140 \mathrm{M} 00 \mathrm{rpm}$, Liebisch Labortechnik (Germany, Bielefeld) samples concentrator in the nitrogen current with the heating capacity up to $130^{\circ} \mathrm{C}$, Stuart Vortex mixer SA8 (UK, Staffordshire) laboratory vortex with the rotation capacity of $2500 \mathrm{rpm}$, Stuart Tube Rotator SB3 (UK, Staffordshire) orbital shaker with the revolving capacity of $40 \mathrm{rpm}$, IKA T 25 digital ULTRATURRAX (Germany, Staufen) dispersant, designed for the volumes from 1 to $2000 \mathrm{ml}$ with a range of rotational frequencies from 3000 to $25000 \mathrm{rpm}$.

QuEChERS method was applied for analysis of residual amounts of avermectins in foods. Reagents from Sigma-Aldrich (Germany) were used to prepare samples and conduct the analysis. The study materials that included samples of raw milk were tested additionally to ensure they did not contain ivermectin residues. The tests were conducted using the method of high-performance liquid chromatography of mass spectrometry. During the study we used the following certified substances: Abamectin, Doramectin, Eprinomectin, Ivermectin and Moxidectin, produced by Sigma Chemical Co. (St. Louis, MO. USA).

To determine $\mathrm{CC}_{\mathrm{a}}$ depending on the MRL and the limits of detection, the control samples were enriched with standard solutions. Evaluation of the method was carried out at the MRL levels of $0 ; 1 ; 1.5$ and 2 .

The main standard solutions at the concentration of $1 \mathrm{mg} / \mathrm{ml}$ of the listed ivermectins were prepared by dissolving in $1 \mathrm{ml}$ of dimethyl sulfoxide and $9 \mathrm{ml}$ of acetonitrile.

The working standard solutions of each ivermectin and the complex standard solution of all ivermectins were prepared by two-stage dilution of the main standard solutions: the first stage -acetonitrile (to the concentration of $10 \mu \mathrm{g} / \mathrm{ml}$ ), the second stage $-0.1 \%$ solution of formic acid in water (to the concentration of $100 \mathrm{ng} / \mathrm{ml}$ ).

Quantitative determination of mass concentration of avermectins in raw milk was done using an external standard method with precalibration of the chromatograph by calibration solutions using the matrix matched standards (MMS). The MMS are based on the milk sample with working solutions of avermectins added to the sample in different concentrations for building a linear calibration curve. Avermectins were identified accordingly to the retention time, the presence of the corresponding ions and their intensity ratios. To determine the content of avermectins in solution were used UHPLC-MS/MS method.

The sample was prepared according to the following scheme: selected milk sample was homogenised in a volume of $50 \mathrm{ml}$ with the aid of the IKA T 25 digital ULTRA-TURRAX dispersant, then degreased by centrifugation at $4500 \mathrm{rpm}$ and $4^{\circ} \mathrm{C}$ for $10 \mathrm{minutes}$, a mixture of standard solutions was added to $10 \mathrm{~g}$ of milk. After shaking, $10 \mathrm{ml}$ of acetonitrile were added for extraction. After homogenizing the test sample for 30 seconds $1 \mathrm{~g}$ of sodium chloride and $4 \mathrm{~g}$ of magnesium sulfate were introduced into the sample using the dispersant, followed by manual shaking for $1 \mathrm{~min}$. Then centrifugation was performed within 10 minutes at radial acceleration of $4000 \mathrm{rpm}$. After centrifuging the sample, the supernatant was taken up in a polypropylene tube in which $1.5 \mathrm{~g}$ of magnesium sulfate and $0.5 \mathrm{~g}$ of octadecyl-modified silica gel (C18) were previously added and mixed in vortex for $30 \mathrm{~s}$. After this, the sample was centrifuged at $4500 \mathrm{rpm}$ and $4^{\circ} \mathrm{C}$ for 10 minutes, the supernatant layer was taken in a $15 \mathrm{ml}$ test tube, in which 250 $\mu \mathrm{l}$ of dimethyl sulfoxide was pre-introduced, and mixed in vortex for $30 \mathrm{~s}$ and the acetonitrile layer was evaporated under a stream of nitrogen at a temperature of $50^{\circ} \mathrm{C}$. The remained after evaporation dimethyl sulfoxide was put to the vial for injection through the syringe filter $(0.2 \mu \mathrm{m} 13 \mathrm{~mm}$ Acrodisc Syringe Filter GHR, USA, Milford). The study of the content of avermectins in raw milk was performed on a triple quadrupole mass spectrometer Waters XEVO TQ-S micro (USA). The voltage of the electric spray was set at the level of $3.0 \mathrm{~kW}$ for positive mode. Desolvation and source temperatures were set at 450 and $150^{\circ} \mathrm{C}$, respectively. The drying gas was nitrogen with a flow of $900 \mathrm{~L} / \mathrm{hr}$, the collision gas - argon. Chromatography of the samples was carried out in gradient mode, a system of $0.1 \%$ solution of formic acid in water $(A) /$ acetonitrile $(B)$, and flow rate of $0.6 \mathrm{ml} / \mathrm{min}$ that was changed gradually, depending on the time of the procedure: $0-0.5 \min -100 \% A ; 1-3 \min -50 \% A ; 3.1-10 \mathrm{~min}-10 \% A, 10.1-13$ min $100 \% \mathrm{~A}$. The temperature of the chromatographic column was set at $40^{\circ} \mathrm{C}$. The sample injection mode was automatic; the volume of injection was $10 \mu \mathrm{L}$. Data scan parameters are shown in Table 1. 
Table 1. Scan parameters for conducting trials on the triple quadrupole mass spectrometer.

\begin{tabular}{|c|c|c|c|c|}
\hline Component & $\begin{array}{l}\text { Precursor } \\
\text { Ion }\end{array}$ & $\begin{array}{l}\text { Product } \\
\text { ions }\end{array}$ & $\begin{array}{l}\text { Voltage on the } \\
\text { cone }\end{array}$ & $\begin{array}{c}\text { Collision } \\
\text { energy }\end{array}$ \\
\hline \multicolumn{5}{|c|}{ Ivermectins } \\
\hline Doramectin & 916.44 & $\begin{array}{l}593.34 \\
331.32\end{array}$ & 30.00 & $\begin{array}{l}38.00 \\
13.00\end{array}$ \\
\hline Ivermectin & 892.54 & $\begin{array}{l}569.40 \\
307.34\end{array}$ & 30.00 & $\begin{array}{l}21.00 \\
42.00\end{array}$ \\
\hline Moxidectin & 640.49 & $\begin{array}{l}199.11 \\
528.25\end{array}$ & 30.00 & $\begin{array}{l}44.00 \\
13.00\end{array}$ \\
\hline
\end{tabular}

The confirmatory method was validated in accordance with European Commission Decision 2002/657/EC (Commission Decision, 2002). During the validation process, the following parameters were set: specificity, selectivity, accuracy, linearity, internal laboratory reproducibility, recovery, decision limit $(\mathrm{CCa})$ and detection ability $\left(\mathrm{CC}_{\beta}\right)$. All these data were obtained using the InterVal Software of quo data GmbH (Germany).

$\mathrm{CC}_{\mathrm{a}}$ is an important indicator for assessing the validity of confirmatory methods, and $\mathrm{CC}_{\beta}$ - for screening methods.

$\mathrm{CC}_{\mathrm{a}}$ is the limit of the solution, beyond which one can make conclusion with the probability of error a, that the sample is inappropriate. $\mathrm{CC}_{\beta}$ is the smallest content of the test substance that can be detected, identified or quantified in a sample with probability of error $\beta$. All these parameters were determined during applicability evaluation of the milk control samples method (29 samples in total). The samples were pre-analyzed for the absence of target analyte. Enrichment with analyte was done at the levels: $0 ; 1 ; 1.5 ; 2$ MRL (of validation level for 6 parallels each plus 5 calibration points) for the substances with MRL according to regulatory documents (Commission Decision, 2002). Substances for which the MRL was not regulated were validated at the detection limit with equidistant distances. The study has been conducted for 2 days by two operators.

The accuracy of the method was estimated by counting the average deviation of the results obtained for each concentration.

Extract was calculated by concentration of loaded with a certain amount of analyte control samples. $\mathrm{CC}_{\mathrm{a}}$ and $\mathrm{CC}_{\beta}$ were determined according to the calibration curve constructed by enriching various concentrations of the matrix standard as described in ISO 11843 (Capability of detection, 2003).

The $\mathrm{CC}_{a}$ and $\mathrm{CC}_{\beta}$ parameters were calculated in accordance with the international standard ISO 11843-2 (Capability of detection, 2003). The analytical parameters of $\mathrm{CC}_{\mathrm{a}}$ and $\mathrm{CC}_{\beta}$ were calculated using matrix calibration curves and standard deviations. The curves were constructed using a target analyte in correlation with its peak areas. The linearity was demonstrated for all 5 analytes by preparing a five-point matrix-matched calibration curve at concentration levels of $0,5,10,20,30 \mu \mathrm{g} / \mathrm{kg}$ for ivermectin, abamectin, doramectin, eprinomectin and $0,10,20,40,60 \mu \mathrm{g} / \mathrm{kg}$ for moxidectin. The majority of analytes has shown linear regression values greater than 0.98. According to Commission decision (Commission Decision, 2002), when validating analytical methods, the results are considered acceptable if the CV (coefficient of variation) does not exceed the limits specified in Table 2 on different levels.

Table 2. Examples for the reproducibility of CV for the quantitative method in mass fraction analysis.

$\begin{array}{cc}\text { Mass fraction, } \mathbf{\mu g} / \mathbf{k g} & \mathbf{C V}, \mathbf{\%}) \\ <1 & * \\ 1-10 & 32 * \\ 10-100 & 23 \\ 100-1000 & 16\end{array}$

Note. $\left(^{*}\right)$ Hurwitz equation gives unacceptably high values for the mass fractions smaller than $100 \mu \mathrm{g} / \mathrm{kg}$. Therefore, the CV for concentrations lower than $100 \mu \mathrm{g} / \mathrm{kg}$ should be as low as possible

\section{Results and Discussion}

The validation was performed following the 2002/657/EC guidelines (Commission Decision, 2002). The following parameters were assessed: linearity, trueness, within-laboratory repeatability, within-laboratory reproducibility, decision limit (CCa) and detection capability (CC $\beta$ ). The study was conducted using the Inter VAL V.3.4.0.4 Quo data software (Germany) provided validation data for various ivermectins (Tables 3 and 4). The tables below show standard deviations in repeatability and reproducibility in $\mu g$ and variation coefficients in $\%$ as well as recovery at different calibration levels (data obtained after software processing).

Table 3. Critical concentrations of $\mathrm{CC}_{a}$ and $\mathrm{CC}_{\beta}$ for avermectins and the level of interests, $\mu \mathrm{g} / \mathrm{kg}$.

\begin{tabular}{cccc}
\hline Ivermectins & Level of interests & $\mathbf{C C}_{\mathbf{a}}$ & $\mathbf{C C}_{\boldsymbol{\beta}}$ \\
Ivermectin & 10.0 & 12.53 & 16.63 \\
Abamectin & 10.0 & 12.56 & 16.78 \\
Doramectin & 15.0 & 17.74 & 22.96 \\
Eprinomectin & 20.0 & 24.02 & 30.00 \\
Moxidectin & 40.0 & 44.69 & 54.34 \\
\hline
\end{tabular}


The result of an analysis shall be considered noncompliant if the decision limit of the confirmatory method for the analyte is exceeded. If a permitted limit has been established for a substance, the decision limit is the concentration above which it can be decided with a statistical certainty of $1-a$ that the permitted limit has been truly exceeded. For substances listed in Group A of Annex I to Directive $96 / 23 / E C$, the a error shall be $1 \%$ or lower. For all other substances, the a error shall be $5 \%$ or lower (Commission Decision, 2002). It can be seen from Table 4, that in the analysis of samples of milk with a concentration of ivermectin from 10 to $30 \mu \mathrm{g} / \mathrm{kg}$, recovery was from 98 to $110.0 \%$. This rate is within the requirements of Commission Decision 2002/657/EC for ivermectin with the limits from 80 to 110\% (Commission Decision, 2002). As for moxidectin, which was validated at the level of $40 \mu \mathrm{g} / \mathrm{kg}$ (in accordance with the established MRL for this indicator in raw milk) recovery was from 88.7 to $102.6 \%$ at concentrations levels from 20 to $60 \mu \mathrm{g} / \mathrm{kg}$. Variation coefficient of reproducibility of the analysis results on the content of avermectins in raw milk was also within acceptable limits that should not exceed $23 \%$ (Table 2). At levels of interest $10-20 \mu \mathrm{g} / \mathrm{kg}$ this index was rather low for ivermectin (14.2\%), abamectin (13.2\%), doramectin (9.9\%), eprinomectin (10.6\%), and moxidectin with the concentration of $40 \mu \mathrm{g} / \mathrm{kg}(6.4 \%)$. According to Commission decision 657 of 2002 [24], this indicates sufficient precision of this method. The precision of the method was satisfactory for all analytes in both Rel. Sr, (3.3-16.1\%) and Rel. $\mathrm{S}_{\mathrm{w}} \mathrm{R}$, studies $(6.4-$ $19.7 \%$ ), as the CV did not exceed the maximum CV calculated by the Horwitz equation and two thirds of these values, respectively. From the data received, it can be concluded that all the results obtained after calculation of reproducibility and repeatability are within the permissible limits in accordance with EU decision 657/2002 at various levels of validation (Commission Decision, 2002). Validation of the method of determining the residual content of avermectins in raw milk indicates that the use of UHPLC-MS/MS allows obtaining highly accurate data.

Table 4. Repeatability, internal laboratory reproducibility and recovery of avermectins.

\begin{tabular}{|c|c|c|c|c|c|c|}
\hline Ivermectins & $\begin{array}{c}\text { Concentration, } \\
\mu \mathrm{g} / \mathrm{kg}\end{array}$ & $s_{r}, \mu g / \mathbf{k g}$ & Rel. $s_{r r} \%$ & $S_{\mathrm{wR},} \boldsymbol{\mu} \mathbf{g} / \mathbf{k g}$ & Rel. S $\mathrm{wR}_{\mathbf{w}} \%$ & Recovery, \% \\
\hline \multirow[t]{5}{*}{ Ivermectin } & 10.000 & 1.266 & 12.7 & 1.424 & 14.2 & 98.0 \\
\hline & 15.000 & 1.189 & 7.9 & 1.307 & 8.7 & 104.3 \\
\hline & 20.000 & 1.154 & 5.8 & 1.445 & 7.2 & 107.5 \\
\hline & 25.000 & 1.134 & 4.5 & 1.737 & 6.9 & 109.4 \\
\hline & 30.000 & 1.121 & 3.7 & 2.109 & 7.0 & 110.0 \\
\hline \multirow[t]{5}{*}{ Abamectin } & 10.000 & 1.320 & 13.2 & 1.320 & 13.2 & 107.6 \\
\hline & 15.000 & 1.306 & 8.7 & 1.306 & 8.7 & 108.8 \\
\hline & 20.000 & 1.299 & 6.5 & 1.429 & 7.1 & 109.4 \\
\hline & 25.000 & 1.294 & 5.2 & 1.837 & 7.3 & 109.8 \\
\hline & 30.000 & 1.292 & 4.3 & 2.329 & 7.8 & 110.0 \\
\hline \multirow[t]{5}{*}{ Doramectin } & 10.000 & 0.925 & 9.2 & 0.994 & 9.9 & 106.5 \\
\hline & 15.000 & 0.956 & 6.4 & 1.235 & 8.2 & 103.1 \\
\hline & 20.000 & 0.972 & 4.9 & 1.531 & 7.7 & 101.4 \\
\hline & 25.000 & 0.982 & 3.9 & 1.860 & 7.4 & 100.4 \\
\hline & 30.000 & 0.989 & 3.3 & 2.209 & 7.4 & 99.7 \\
\hline \multirow[t]{5}{*}{ Eprinomectin } & 10.000 & 1.608 & 16.1 & 1.972 & 19.7 & 95.7 \\
\hline & 15.000 & 1.507 & 10.0 & 2.081 & 13.9 & 102.1 \\
\hline & 20.000 & 1.461 & 7.3 & 2.120 & 10.6 & 105.3 \\
\hline & 25.000 & 1.434 & 5.7 & 2.081 & 8.3 & 107.2 \\
\hline & 30.000 & 1.418 & 4.7 & 1.954 & 6.5 & 108.5 \\
\hline \multirow[t]{5}{*}{ Moxidectin } & 20.00 & 2.287 & 11.4 & 2.475 & 12.4 & 88.7 \\
\hline & 30.00 & 2.120 & 7.1 & 2.123 & 7.1 & 95.7 \\
\hline & 40.000 & 2.045 & 5.1 & 2.541 & 6.4 & 99.2 \\
\hline & 50.000 & 2.003 & 4.0 & 3.348 & 6.7 & 101.2 \\
\hline & 60.000 & 1.976 & 3.3 & 4.308 & 7.2 & 102.6 \\
\hline
\end{tabular}

\footnotetext{
Notes: $\mathbf{s}_{\mathbf{r}}-$ repeatability standard deviation; Rel. $\mathbf{s}_{\mathbf{r}}-$ coefficient of repetition variation is listed in \%; $\mathbf{s}_{\mathbf{w R}}-$ in-house reproducibility standard deviation; Rel. $\mathbf{S}_{\mathbf{w R}}-$ coefficient of reproducibility variation, listed in $\%$.

The accredited domestic laboratories of veterinary medicine use mainly screening procedures for determination of safety indicators of raw food products of animal origin. At the same time, in case of receiving positive screening results, it is necessary to conduct the study in accredited laboratories using confirmatory methods, such as the method described (according to the decision of the EU $657 / 2002$ - for the implementation of the National Plans of the State Monitoring of residual quantities of veterinary preparations and pollutants in the body of live animals, products of animal origin and feed, as well as food products under the control of the veterinary service). Within the National Plan of the State Monitoring, during 2016-2018, the Research Laboratory of the ChemicalToxicological department of the State Scientific and Research Institute of Laboratory Diagnostics and Veterinary and Sanitary Expertise analyzed 412 samples of products of animal origin for the residual content of veterinary preparations. Measurements of residual content of ivermectin and abamectin in livers of animals were performed. Owing to the validated method, the expansion of the State Monitoring Plan is scheduled for 2020. And the expansion is not limited to the addition of a new matrix - raw milk, but also foresees adding more avermectines to the list, including doramectin, eprinomectin and moxidectin. We also carried out the research on 26 samples of raw milk received from milk producers in 2019. The results of the research showed that the remains of erprinomectin were found in the milk samples in quantities below CCa. Thus, the above listed results of research have shown that today in Ukraine there is the necessity of the State Monitoring and Control Plan of avermectin residues such as eprinomectin, doramectin and moxidectin.
} 


\section{Conclusion}

During the study we assessed the applicability of UHPLC-MS/MS method, established the MS/MS detection parameters and determined its validation characteristics for the analysis of residual content of ivermectins in raw milk. This method is accurate, practical and universal. This is confirmed by the obtained CCa data: abamectin $-12.56 \mu \mathrm{g} / \mathrm{kg}$, doramectin $-17.74 \mu \mathrm{g} / \mathrm{kg}$, eprinomectin - $24.02 \mu \mathrm{g} / \mathrm{kg}$, ivermectin - $12.53 \mu \mathrm{g} / \mathrm{kg}$ and moxidectin $-44.69 \mu \mathrm{g} / \mathrm{kg}$. Recovery for avermectins used for the method validation is $88.7-110 \%$. These results meet the requirements of European Directives. The QuEChERS procedure for extraction of avermectins was modified in the laboratory. It involves simple procedure of samples' preparation and doesn't require any costly materials for solid-phase cleaning. These benefits provide economic efficiency, speed and high throughput capacity of the analysis of residual amounts of avermectins in food products, including raw milk. The developed and adopted for the routine use at the laboratories of veterinary medicine UHPLC-MS/MS method for detection residual amounts of avermectins could be used in animal breeding of the Ukraine.

\section{References}

Baoliang, P., Yuwan, W., Zhende, P., Lifschitz, A.L., Ming W. (2006). Pharmacokinetics of Eprinomectin in Plasma and Milk Following Subcutaneous Administration to Lactating Dairy Cattle. Vet Res Commun, 30(3), 263-270. https://doi.org/10.1007/s11259-0063230-7

Codex Alimentarius. Maximum residue limits (MRLs) and risk management recommendations (RMRs) for residues of veterinary drugs in foods CAC/MRL. 2e2014. Updated as at the 37th Session of the Codex Alimentarius Commission (July 2014)

Commission Decision 2002/657/EC, 2002. Implementing Council Directive 96/23/EC concerning the performance of analytical methods and the interpretation of results. Off. J Europ Comm, No. L 221/8. http://eur-lex.europa.eu/smartapi/cgi/sga_doc?smartapi Commission Regulation (EU) No:37/2010 of 22 December 2009 on pharmacologically active substances and their classification regarding maximum residue limits in foodstuffs of animal origin. Official Journal of the European Union. 20.01.2010. L15/1

Danaher, M., Howells, L.C., Crooks, S.R.H., Cerkvenik-Flajs, V., O'Keeffe, M. (2006). Review of Methodology for the Determination of Macrocyclic Lactone Residues in Biological Matrices. J Chromatogr B Analyt Technol Biomed Life Sci., 844 (2), $175-203$. https://doi.org/10.1016/j.jchromb.2006.07.035

de Souza Santos Cheibub, A. M., Silva Bahiense de Lyra, E., Pereira Netto, A. D. (2019) Development and validation of a method for simultaneous determination of trace levels of five macrocyclic lactones in cheese by HPLC-fluorescence after solid-liquid extraction with low temperature partitioning. Food Chem., 272, 148-156. https://DOI:10.1016/j.foodchem.2018.08.027

Dupuy, J., Chartier, C., Sutra, J. F., Alvinerie, M. (2001). Eprinomectin in Dairy goats: Dose Influence on Plasma Levels and Excretion in Milk. Parasitology Research, 84(7), 294-298. https://doi.org/10.1007/PL00008581

Durden, D. A. (2007). Positive and negative electrospray LC-MS-MS methods for quantitation of the antiparasitic endectocide drugs, abamectin, doramectin, emamectin, eprinomectin, ivermectin, moxidectin and selamectin in milk. J Chromatogr B Analyt Technol Biomed Life Sci., 850 (1-2), 134-46. https://doi.org/10.1016/j.jchromb.2006.11.014

Giannetti, L., Giorgi, A., Necci, F., Ferretti, G., Buiarelli, F., Neri, B. (2011). Validation Study on Avermectin Residues in Foodstuffs. Anal Chim Acta, 700 (1-2), 11-15. . https://DOI:10.1016/j.aca.2010.12.035

He, J., Hou, X., Jiang, H., Shen, J. (2005). Multiresidue analysis of avermectins in bovine liver by immunoaffinity column cleanup procedure and liquid chromatography with fluorescence detector. J AOAC Int, 88 (4), 1099-103.

Huang, J. X., Lu, D. H., Wan, K., Wang, F. H. (2014). Low Temperature Purification Method for the Determination of Abamectin and Ivermectin in Edible Oils by Liquid Chromatography-Tandem Mass Spectrometry. Chinese Chemical Letters, 25 (4), $635-639$. https://doi.org/10.1016/j.cclet.2014.01.036

ISO 11843 Capability of detection. (2003). Part 1: Terms and definitions, Part 2: Methodology in the linear calibration case.

Kaufmann, A., Butcher, P., Maden, K., Walker, S., Widmer, M. (2014). Multi-Residue Quantification of Veterinary Drugs in Milk with a Novel Extraction and Cleanup Technique: Salting out Supported Liquid Extraction (SOSLE). Anal Chim Acta. Apr 11, 820, 56-68. https://doi.org/10.1016/j.aca.2014.02.038.

Kose, L. P., Gülçin, İ., Özdemir, H., Atasever, A., Alwasel, S. H., Supuran, C. T. (2016). The effects of some avermectins on bovine carbonic anhydrase enzyme. J Enzyme Inhib Med Chem., 31 (5), 773-778. https://doi.org/10.3109/14756366.2015.1064406

Lumaret, J. P., Errouissi, F., Floate, K., Römbke, J., Wardhaugh, K. (2012). A Review on the Toxicity and Non-Target Effects of Macrocyclic Lactones in Terrestrial and Aquatic Environments. Curr. Pharm. Biotechnol, 13(6), 1004-1060.

Manjusha, R., Jadhav, Anjali Pudale, Prakash Raut, Sagar Utture, Kaushik Banerjee. (2019). A unified approach for high-throughput quantitative analysis of the residues of multi-class veterinary drugs and pesticides in bovine milk using LC-MS/MS and GC-MS/MS. Food Chem, 272, 30, 292-30. https://doi.org/10.1016/j.foodchem.2018.08.033

Miyajima, A., Hirota, T., Sugioka, A., Fukuzawa, M., Sekine, M., Yamamoto, Yo., Yoshimasu, T., Kigure, A. (2016). Effect of high-fat meal intake on the pharmacokinetic profile of ivermectin in Japanese patients with scabies. J Dermatol, 43 (9), 1030-1036. https://doi.org/10.1111/1346-8138.13321

Nurullah Ozdemir, Tahir Kahraman (2016). Rapid confirmatory analysis of avermectin residues in milk by liquid chromatography tandem mass spectrometry. Journal of Food and Drug Analysis, 24 (1), 90-94. https://doi.org/10.1016/j.jfda.2015.07.004

Ortiz, A. J., Cortez, V., Azzouz, A., Verdú, J. R. (2017). Isolation and determination of ivermectin in post-mortem and in vivo tissues of dung beetles using a continuous solid phase extraction method followed by LC-ESI+-MS/MS. PLoS One, 12(2). https://doi.org/10.1371/journal.pone.0172202

Sheridan, R., Desjardins, L. (2006). Determination of abamectin, doramectin, emamectin, eprinomectin, ivermectin, and moxidectin in milk by liquid chromatography electrospray tandem mass spectrometry. J AOAC Int, 89(4), 1088-94.

Tengteng, Ni., Dapeng Peng., Yanxin Wang., Yuanhu Pan., Shuyu Xie., Dongmei Chen., Yulian Wang., Yanfei Tao., Zonghui Yuan. (2019). Development of a broad-spectrum monoclonal antibody-based indirect competitive enzyme-linked immunosorbent assay for the multi-residue detection of avermectins in edible animal tissues and milk. Food Chemistry. 2019, 286, 234-240. https://doi.org/10.1016/j.foodchem.2019.02.011

Voitsitskiy, V. M., Danchuk, V. V., Ushkalov, V. O., Midyk, S. V., Kepple, O. Yu., Danchuk, O. V., Shevchenko, L. V. Migration of antibiotics residual quantities in aquatic ecosystems (2019). Ukrainian Journal of Ecology, 9(3), 280-286. 
Wu, Z., Li, J., Zhu, L., Luo, H., Xu, X. J. (2001). Multi-residue analysis of avermectins in swine liver by immunoaffinity extraction and liquid chromatographyemass spectrometry. J Chromatogr B Biomed Sci Appl, 755 (1-2), 361-6. https://doi.org/10.1016/S03784347(01)00077-9

Yakubchak, O. M., Laposha, S. V., Midyk, S. V., Taran, T. V., Zabarna, I. V. (2018). Assessment of the Conformity of the Methods for Aflatoxin B1 and Deoxynivalenol Determination in Grain and Feeds by Method of High-Performance Liquid Chromatography. Methods Objects Chem. Anal, 13(3), 121-130. https://doi.org/10.17721/moca.2018.121-130

Yashpal, S., Chhonker., Liping Ma., Constant Edi., Daryl A. (2018). Sensitive and selective LC-MS/MS method for quantitation of ivermectin in human, mouse and monkey plasma: clinical validation. Bioanalysis, 10(22). https://doi.org/10.4155/bio-2018-0110

\section{Citation:}

Bayer, O.V., Kaminska, O.V., Bondarets, O. V., Yaremchuk, O. S., Skoromna, O. I., Midyk, S. V., Shevchenko, L. V., Mykhalska, V. M., Stupak, O. M., Liniichuk, N. V. (2019). Evaluation of Ultra-High-Performance Liquid Chromatography Tandem Mass Spectrometry for Determination of Avermectin Residues in Milk. Ukrainian Journal of Ecology, 9(4), 521-526.

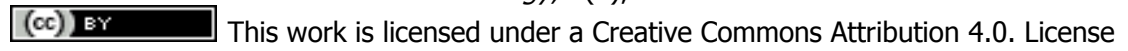

